\title{
FORMAÇÃO DOS PROFESSORES DE HISTÓRIA: \\ EDUCAÇÃO HISTÓRICA, PESQUISA E PRODUÇÃO DE \\ CONHECIMENTO
}

\author{
OF HISTORY TEACHER TRAINING: \\ HISTORICAL EDUCATION, RESEARCH AND KNOWLEDGE PRODUCTION
}

Adriane Quadros Sobanski ${ }^{1}$

\begin{abstract}
RESUMO: Este estudo trata das primeiras observações acerca dos trabalhos desenvolvidos por professores da Educação Básica de Escolas Públicas, estaduais e municipais, da cidade de Curitiba, Paraná. Colocados frente a possibilidades de desenvolver pesquisa e realizar investigações para sua prática cotidiana da sala de aula. esses professores desenvolveram atividades a partir do contato com fontes históricas primárias conservadas no Arquivo Público do Estado do Paraná. Participando, orientando e observando um grupo de cerca de 30 professores de História que participou ao longo de 2013 do curso $O$ trabalho com fontes históricas e a literacia histórica: questões teóricas e práticas, ministrado pela professora Maria Auxiliadora Schmidt da Universidade Federal do Paraná, iniciei as investigações relativas ao trabalho desenvolvido por esses professores com base no contato com a teoria da Educação Histórica e a sua prática da sala de aula.
\end{abstract}

Palavras-chaves: Educação Histórica. Aprendizagem. Pesquisa.

\begin{abstract}
This study deals with the first observations on the projects developed by teachers of basic education of Public, State and municipal Schools, the city of Curitiba, Paraná. Placed in front of possibilities to develop research and perform investigations for your everyday classroom practice, these teachers have developed activities from contact with primary historical sources preserved in the public record of the State of Paraná. Participating, guiding and observing a group of about 30 teachers of History who participated throughout the course work with 2013 historical sources and historical literacy: theoretical and practical issues, taught by Professor Maria Auxiliadora Schmidt of the Federal University of Paraná, started the investigations relating to the work done by these teachers based on contact with the theory of Historical Education and its practice in the classroom.
\end{abstract}

Keywords: Historical Education. Learning. Research.

\footnotetext{
${ }^{1}$ Professora da rede pública de ensino do Estado do Paraná. Mestre e Doutoranda pela UFPR.
} 


\section{Introdução}

As Diretrizes Curriculares Nacionais do Curso de História (2001) afirmam que a formação dos professores de História deve ser baseada no exercício da pesquisa, porém esta parece não ser uma realidade comum aos profissionais do ensino de História da Educação Básica, os quais estão habituados a utilizar o conhecimento sistematizado por outros pesquisadores, principalmente pelos autores de manuais didáticos.

Este artigo trata das primeiras considerações acerca do papel dos professores enquanto produtores de conhecimento e sua relação com a pesquisa. Toma-se como ponto de partida a ideia decorrente de estudos pedagógicos que consideram os professores, no caso específico desta pesquisa, que atuam com a disciplina de História, como culpados pela má qualidade da educação e meros reprodutores de conhecimento.

Integrante da equipe de História do Departamento de Educação Básica da Secretaria de Estado da Educação do Paraná (SEED) entre fevereiro de 2013 e junho de 2014, tive a oportunidade de participar mais ativamente com a formação continuada de professores da rede estadual. Uma dessas experiências aconteceu quando, em parceria com o Núcleo Regional de Educação de Curitiba e a Professora Dra. Maria Auxiliadora Schmidt, por meio do LAPEDUH ${ }^{2}$, a SEED promoveu um curso para professores de História de Curitiba.

O trabalho com fontes históricas e a literacia histórica: questões teóricas e práticas, curso realizado desde 2010 pela Secretaria Municipal de Educação de Curitiba, vem mostrando muitos resultados positivos. A possibilidade de atendimento aos professores de História da rede Estadual, envolvendo aqueles que atuam na cidade de Curitiba, foi muito bem vinda pela SEED.

Assim, 30 professores de História da Rede Estadual integraram o primeiro grupo envolvido nesse projeto, realizando seu trabalho pautado na perspectiva de professores-pesquisadores.

Entendendo que o ponto de partida do ensino de História é sempre o passado que está no presente e é através dele que tentamos entender as experiências humanas no passado, a experiência do curso, ministrado pela

\footnotetext{
${ }^{2}$ Laboratório de Pesquisa em Educação Histórica.
} 
professora Maria Auxiliadora Schmidt, possibilitou a percepção de que os professores, diante situações de pesquisa, mobilizam a consciência histórica de estudantes, estimulando a aprendizagem e produzindo conhecimento.

Após o longo período em que a educação brasileira foi controlada e manipulada pelos interesses da Ditadura Militar, o ensino de História no Brasil passou por um processo de revitalização e de novos propósitos. A década de 1980, nesse sentido, foi muito importante para as novas discussões que surgiram em torno da forma como a História, sobretudo com relação ao seu retorno aos currículos escolares, seria tratada pela cultura escolar, o que caminhava junto com propostas nacionais sobre mudanças no que e como ensinar o conhecimento histórico escolar.

Com forte influência do Marxismo, da Nova Escola e da Historiografia inglesa, o objetivo da História passou a ser o de recuperar o aluno como sujeito da história e não como mero expectador de uma história já determinada, produzida por heroicos personagens dos livros didáticos. Foi assim que no estudo da História houve a introdução de novos sujeitos sociais que até então eram considerados insignificantes, caso das mulheres e dos trabalhadores.

Foi durante esse período de resgate da disciplina que a preocupação com o papel dos professores passou a ser discutido, havendo reflexões iniciais sobre a formação de professores-pesquisadores. A adoção de práticas de investigação pelo professor acerca do seu próprio campo de atuação torna-se assim relevante, a fim de tornar o profissional da docência consciente da sua própria profissão assumindo a postura de sujeito pensante e de um profissional intelectual. No que se refere à História podemos registrar discussões sobre o assunto, de forma sistematizada, a partir dos anos de 1990 (FONSECA, 2003; SCHMIDT; CAINELLI, 2009).

Porém, como afirma Theobald (2007) "a prática educativa escolar tem sido abordada muito mais pela sua natureza de transmissão de conhecimentos ensino, e não como produtora de conhecimentos - pesquisa."

Para que essa prática educativa se realize em função da atividade de pesquisa, no entanto, é necessário que sejam fornecidos os meios adequados para a produção do conhecimento, assim como que as condições materiais para que isso ocorra sejam oferecidas. 
Somando-se a essa necessidade de repensar o papel dos professores, a Educação Histórica, pautada na teoria do alemão Jörn Rüsen, vem colaborar com novas discussões sobre o ensino de História e, de forma imprescindível, sobre as ações dos professores-pesquisadores.

A realização de cursos de formação de professores pautados na perspectiva da Educação Histórica teve como momento de fundamental importância o ano de 2003, quando a professora Maria Auxiliadora iniciou encontros regulares para estudo e desenvolvimento de pesquisa com os professores do Município de Araucária. Criando uma identidade particular, esses professores passaram a ser reconhecidos como "Grupo Araucária."

Integrante desse grupo, Theobald, em sua Dissertação de Mestrado afirma:

(...) o professor, em sua experiência de relação com o saber, pode ser tomado na dimensão de intelectual que investiga, produz e transforma pelas experiências organizadas, coletivas e situadas, as relações sociais e as relações de saber em que está inserido. Ademais, ele também investiga e transforma as concepções que tem em relação a si próprio e à sua função; aos alunos em suas relações com o saber; à relação com a sua formação e à relação com conhecimento com o qual trabalha sua produção e seu ensino. (THEOBALD, 2007, p. 41)

Em 2010 um curso pautado nessa mesma perspectiva da Educação Histórica, também sob orientação da Prof. a Maria Auxiliadora Schmidt, passou a fazer parte da política de formação de professores da Rede Municipal de Educação. Desde então, aqueles professores têm desenvolvido diversas pesquisas, aplicando-as a sua realidade escolar, bem como realizando apresentações acerca de suas experiências e produções nos mais diversos encontros sobre ensino de História.

No caso da Rede Estadual, com uma política de corte de gastos, desde 2010 a Secretaria de Estado da Educação oferece, como cursos de formação continuada para os professores que atuam na rede: a Semana Pedagógica, que ocorre no início e na metade do ano; o Programa de Desenvolvimento 
Educacional (PDE) ${ }^{3}$; o Grupo de Trabalho em Rede (GTR ${ }^{4}$ e a Formação em Ação, curso que se realiza duas vezes ao ano num total de 16 horas. Constatase, com esses dados, que nos últimos anos o Estado do Paraná tem oferecido poucas possibilidades de formação continuada aos professores da Rede Estadual de Educação.

Além de considerar a importância da Educação Histórica na formação dos professores, esse foi, também, um dos motivos pelos quais, em parceria com o LAPEDUH, a equipe de História do Departamento de Educação Básica da Secretaria de Estado da Educação conseguiu efetivar a organização e oferta do curso ministrado pela professora Maria Auxiliadora Schmidt para os professores de História que atuam em Curitiba.

\section{A pesquisa matriz:}

Nesse contexto em que se busca refletir sobre o papel dos professores enquanto pesquisadores e sujeitos pensantes sobre sua própria prática, a Educação Histórica oferece as ferramentas teóricas e metodológicas para esta pesquisa, sobretudo a partir da observação e análise da participação efetiva de 30 professores da Rede Estadual de Ensino no curso $O$ trabalho com fontes históricas e a literacia histórica: questões teóricas e práticas, ministrado pela professora Dra Maria Auxiliadora Schmidt.

O curso se baseou na relação entre teoria e prática, considerada extremamente importante para a atuação de qualquer profissional de educação. Assim, contando com uma orientação teórica acerca da Educação História e dos elementos que a embasam, os professores foram conduzidos a uma nova proposta de trabalho: seleção de uma fonte histórica primária no Arquivo Público do Paraná, a qual deveria ser relacionada a um conteúdo específico trabalhado em sala de aula, independente do ano em que lecionassem. Foi assim que,

\footnotetext{
${ }^{3}$ Programa do Estado do Paraná, em parceria com professores do Ensino Superior, em busca da realização de pesquisa e aplicação da teoria-prática na formação dos professores da Rede Estadual de Ensino.

${ }^{4}$ Este curso, ofertado à distância, é ministrado pelos professores que acabam o PDE e tem, nesse momento, a oportunidade de colocar em prática a pesquisa desenvolvida durante o curso de duração de 1 ano.
} 
durante três visitas técnicas realizadas àquela instituição, os professores foram guiados pela historiadora responsável na escolha da fonte, procurando relacionar esse documento a um determinado conteúdo que fizesse parte de seu planejamento.

Aquilo que denominamos de conteúdos históricos, são tratados pela Educação Histórica enquanto Conceitos Substantivos. Peter Lee (2005), afirma que "como parte do conteúdo de história, conceitos substantivos são, geralmente, centrais em relação ao que nós pensamos de nós mesmos enquanto lecionamos". Tal denominação tem suas origens a partir de uma categoria desenvolvida por Jörn Rüsen e definida como Conceito Histórico. De acordo com Rüsen (2007), esses conceitos são recursos linguísticos utilizados como forma de definir como o pensamento histórico científico se realiza. Tais conceitos são sempre referidos por nomes próprios e têm qualidades históricas pré-esboçadas pelas categorias históricas. Os conceitos de segunda ordem ou conceitos estruturais relacionados à História, isto é, sobre noção de verdade, evidência, temporalidade, evidência, causalidade, mudança, etc. (LEE, 2003).

A construção de uma literacia histórica ocorre na interdependência entre os conceitos substantivos e os conceitos de segunda ordem. Entretanto, os conceitos históricos substantivos provavelmente sejam mais priorizados nas aulas de história em detrimento dos conceitos estruturais ou conceitos de segunda ordem.

\section{Professores pesquisadores e a Educação Histórica}

A orientação para que haja uma formação em pesquisa se encontra presente nas Diretrizes Curriculares Nacionais do Curso de História (Parecer CNE/CES 492/2001), tanto nas competências, habilidades requeridas ao profissional em formação, como nos conteúdos básicos e complementares da área a serem organizados em torno dos "conteúdos histórico/historiográficos e práticas de pesquisa que, sob diferentes matizes e concepções teóricometodológicas, definem e problematizam os grandes recortes espaço-temporais" (BRASIL, DCNs, 1998: p. 8). 
Para muitos dos professores participantes do curso a ida ao Arquivo Público significou um primeiro contato com a instituição e com fontes primárias, significando que a maioria deles não possuía o hábito de lidar com esse tipo de material durante suas aulas e, principalmente, de trabalhar por meio da pesquisa. A produção do conhecimento era entendida como algo que acontecia apenas na academia e como se o seu papel fosse apenas o de reprodução do conhecimento histórico.

Rüsen (2012), afirma que existe uma grande diferença entre os historiadores e os professores de História devido à demanda prática ou funcional da didática da História. Tal diferença se encontra no sentido de que os historiadores carecem daquilo que Rüsen chama de "perícia acadêmica" e "competência acadêmica", ou seja, a capacidade de lidar com o saber histórico produzido cientificamente e, eventualmente, produzir por conta própria tal saber, mas, em todo caso, ser capaz de disponibilizá-lo onde ele for necessário. (Rüsen, 2012, p. 117).

Essa perícia encontra seu lugar, justamente, na escola, espaço que favorece o trabalho e a produção de conhecimento histórico por parte dos professores.

É afinal, a necessidade de formar professores que constitui a didática da História como instituição. Exatamente na medida em que a educação de crianças por meio do saber histórico é por princípio diferente do trabalho com o saber histórico na ciência, faz parte dela uma competência que já não é idêntica à perícia de historiadores profissionais. (RÜSEN, 2012, p. 117)

De acordo com Rüsen (2012), "a didática da História se situa nessa relação direta com a ciência da História, na medida em que se concebe como ciência da transmissão do conhecimento histórico produzido pela ciência da História". Dessa forma, a esses professores, foram oferecidas as primeiras ferramentas para a compreensão da importância que possuem com relação à aprendizagem em História.

Ao selecionar as fontes que seriam utilizadas em sua pesquisa, os professores puderam perceber que

"se a investigação histórica deve estar no centro do currículo de História e ser reconhecida como um empreendimento 
sério nas aulas de História, então o principal para o currículo e para o empreendimento deve ser o desenvolvimento dos conceitos de evidência histórica pelos alunos". (ASHBY, 2006, p. 153-154)

Rüsen (2010), ao anunciar a importância da Didática da História, afirma que há uma forte necessidade de perceber a História como uma "disciplina específica que possui as suas próprias questões, concepções teóricas e operações metodológicas". Assim, o contato com as fontes se revelou aos professores sujeitos desta pesquisa - uma oportunidade de voltar a se reconhecerem como produtores de conhecimento. Dessa forma, a seguir são apresentadas algumas fontes e os conceitos substantivos selecionados pelos professores para a realização dos seus trabalhos.

\begin{tabular}{|c|c|}
\hline Fontes & Temáticas selecionadas \\
\hline $\begin{array}{lll}\text { Propaganda } & \text { de } & \text { Nazismo } \\
\text { (Fosfotoni). } & & \end{array}$ & Regimes totalitários \\
\hline $\begin{array}{l}\text { Lendas de Nossa Senhora da Luz } \\
\text { dos Pinhais e de Cúri-tim e Acta do } \\
\text { levantamento do Pelourinho. }\end{array}$ & Fundação da cidade de Curitiba \\
\hline $\begin{array}{l}\text { Times de futebol da capital } \\
\text { paranaense (Atlético, Coritiba e } \\
\text { Paraná Clube). }\end{array}$ & Imigração \\
\hline Mineração no Paraná. & $\begin{array}{l}\text { Exploração de ouro em Campo } \\
\text { Magro. }\end{array}$ \\
\hline $\begin{array}{l}\text { Relatórios de governo: incentivo } \\
\text { aos imigrantes referências aos } \\
\text { indígenas. }\end{array}$ & História local e identidade \\
\hline IML de Curitiba na década de 1930. & A morte em diferentes culturas \\
\hline $\begin{array}{l}\text { Dossiê do DOPs do Jardim de } \\
\text { Infância Pequeno Príncipe. }\end{array}$ & Ditadura Militar em Curitiba \\
\hline Irmandades Negras de Curitiba. & O negro na História do Brasil \\
\hline $\begin{array}{l}\text { Passaporte do imigrante libanês } \\
\text { José Antônio Mansur. }\end{array}$ & Imigração \\
\hline
\end{tabular}




\begin{tabular}{|l|c|}
\hline Relatórios de Presidentes da & História e Cultura afrobrasileira e \\
Província do Paraná (1854/1858). & indígena.
\end{tabular}

\title{
Tabela 1: Fontes e temáticas
}

Para que esses professores pudessem desenvolver a sua pesquisa, primeiramente precisaram retomar o conceito de fonte histórica, bem como a ideia de que a ida ao passado só tem sentido se a "experiência do passado é interpretada e, com ela, as mudanças temporais do presente são entendidas e o futuro, esperado". (RÜSEN, 2012, p. 42).

Com as fontes é possível ir até uma determinada parte do passado realizando uma investigação sistematizada, por isso a necessidade de selecionar um conteúdo próprio da História.

\begin{abstract}
Pode-se depreender que o ensino de História necessita prestar atenção à natureza das afirmações históricas conjuntamente aos trabalhos em que alunos se ocupam com as fontes. Se os alunos devem desenvolver um conceito de evidência, eles necessitarão compreender a relação de evidência entre as fontes históricas (compreendias a partir de um conceito de que foi a sociedade quem as produziu), e as afirmações sobre o passado que elas apoiam. (ASHBY, 2006, p. 155)
\end{abstract}

As investigações realizadas por esse grupo de professores foi inserida nos pressupostos da Educação Histórica, tendo os referenciais teórico-metodológicos específicos.

Metodologicamente, a condução de suas pesquisas, de cunho qualitativo, seguiu os mesmos passos: investigação dos conhecimentos prévios, apresentação e análise das fontes históricas selecionadas e articuladas aos conteúdos curriculares e, finalmente, a produção de narrativas históricas por parte dos estudantes envolvidos nas pesquisas.

Ora se o professor estiver empenhado em participar numa educação para o desenvolvimento, terá de assumir-se como investigador social: aprender a interpretar o mundo conceitual dos seus alunos, não para de imediato o classificar em certo/errado, completo/incompleto, mas para que esta sua compreensão o ajude a modificar positivamente a conceitualização dos alunos, tal como o construtivismo social propõe. (BARCA, 2004: p. 2). 


\section{Categorização: entre a teoria e a prática}

Durante uma conversa realizada no último encontro do curso com os professores-pesquisadores, foi possível anotar algumas ideias apresentadas do que pensam sobre o que é a pesquisa e da sua importância para as aulas de História.

\begin{tabular}{|c|l|}
\hline \multicolumn{3}{|c|}{ Ideias de pesquisa apresentadas pelos professores } \\
\hline $\begin{array}{c}\text { Professor } \\
\text { Idimar }\end{array}$ & Separação entre professor e historiador/pesquisador. \\
\hline $\begin{array}{c}\text { Professor } \\
\text { Marcio }\end{array}$ & $\begin{array}{l}\text { Resgate da experiência dos estudantes e ampliação } \\
\text { das informações por parte do professor. }\end{array}$ \\
\hline $\begin{array}{c}\text { Professora } \\
\text { Cristina }\end{array}$ & $\begin{array}{l}\text { Forma como o aluno aprende: usar a pesquisa como } \\
\text { parâmetro para a aprendizagem. }\end{array}$ \\
\hline $\begin{array}{c}\text { Professora } \\
\text { Angela }\end{array}$ & $\begin{array}{l}\text { Construir/solidificar o conteúdo com base na } \\
\text { historiografia. }\end{array}$ \\
\hline $\begin{array}{c}\text { Professora Ana } \\
\text { Domínio de um conhecimento/conteúdo específico. }\end{array}$ \\
\hline Professor Tiago & $\begin{array}{l}\text { Construir a História e registrá-la (teoria e prática). } \\
\text { Existe uma diferença entre a pesquisa da licenciatura } \\
\text { e a outra para o bacharelado. }\end{array}$ \\
\hline
\end{tabular}

Tabela 2: Ideias dos professores

Percebe-se, com essas respostas, que ainda existe certo conflito entre o que entendem enquanto pesquisa e a forma como pensam trabalhar com essa metodologia própria da ciência de referência.

O professor Idimar, por exemplo, relembra a velha dicotomia existente na formação dos cursos de História que reforça a ideia de que existem aqueles profissionais que fazem parte do mundo acadêmico, dominando os recursos e a prática da pesquisa e aqueles, saídos da licenciatura, os professores, entendidos exclusivamente como reprodutores do conhecimento produzido pela academia. Da mesma forma o professor Tiago relembra essa dicotomia e aponta a necessidade de articulação entre a teoria e a prática, atitude tão cara à Educação Histórica.

\footnotetext{
${ }^{5}$ Os professores autorizaram que se inserissem seus nomes.
} 
A professora Angela aponta a importância de situar a disciplina na ciência de referência, pois afirma que é preciso "solidificar o conteúdo com base na historiografia".

De acordo com o professor Marcio, a pesquisa é entendida como o momento de estudo por parte de estudantes e professores, sendo por meio dela que os profissionais da História vão se apropriar da produção historiográfica. É possível que, nesse momento, relembre-se de parte de sua experiência durante a graduação, quando teve contato com a historiografia, que deveria orientar seu trabalho. Segundo ele não é necessário que o professor domine todo o conhecimento, mas que deva realizar a pesquisa do que será estudado junto com seus alunos.

Esse mesmo professor afirma que, no que se refere à pesquisa, é preciso perceber que não existe uma mesma metodologia para professores e estudantes, ou seja, para o professor, enquanto produtor de conhecimento, a pesquisa deve ser realizada de uma maneira específica, diferente daquela entendida como processo de aprendizagem dos estudantes.

A pesquisa enquanto parâmetro de avaliação foi a resposta dada pela professora Cristina. De certo modo, nessa resposta, é possível perceber que para essa professora a literacia histórica se apresenta no processo da pesquisa, na relação dos estudantes com as fontes históricas ao interpretá-las, tendo contato com outros passados e se orientando temporalmente.

De acordo com a especificidade de cada um desses professorespesquisadores, foi possível perceber procedimentos diferentes no momento de recolher esses conhecimentos prévios, atividade que não era comum na prática da maioria dos envolvidos. Após esse primeiro momento, percebe-se que alguns professores levaram em consideração as respostas de seus alunos, encaminhando o trabalho com as fontes no sentido de desenvolver uma consciência histórica e de formação da identidade histórica dos estudantes.

Em outras situações os professores se mantiveram presos apenas aos conceitos históricos com os quais estavam lidando, o que pode ser percebido na definição da professora Ana, quando afirma que pesquisa é o "domínio de um conhecimento/conteúdo específico", sem relacionar a fonte selecionada com a vida prática dos seus estudantes ou mesmo com uma possibilidade de orientação 
temporal. Foi perceptível a dificuldade, em alguns casos, de lidar com as fontes enquanto uma possibilidade de explicação acerca do passado, mantendo-se presos a uma única versão do acontecimento.

\section{Considerações finais}

Segundo Isabel Barca, esta linha de investigação busca uma "observação sistemática do real", não se centrando nos "formalismos e recursos da aula", embora estes sejam também importantes, mas nas "ideias históricas de quem aprende e ensina". No entanto, em última instância, o que se tem em meta é a qualidade do ensino de história, ou seja, as práticas em sala de aula (BARCA, 2008, p. 24). Nestes estudos em Educação Histórica, em síntese:

Os investigadores têm entrado a sua atenção nos princípios, fontes, tipologias e estratégias de aprendizagem em História, sob o pressuposto de que a intervenção na qualidade das aprendizagens exige um conhecimento sistemático das ideias históricas dos alunos, por parte de quem ensina (e exige também um conhecimento das ideias históricas destes últimos). Análise destas ideias implica um enquadramento teórico que respeite a natureza do saber histórico e que deve refletir-se, do mesmo modo, na aula de História. (BARCA, 2005, p. 15).

Para Isabel Barca, a análise das ideias prévias dos alunos e professores a partir de um enquadramento teórico que respeite a natureza do saber histórico deve refletir-se na sala de aula (BARCA, 2005, p. 15). Sem problematização dos conhecimentos prévios dos alunos e dos professores, corre-se o risco de restringir a pesquisa na empiria, sem que a qualidade do ensino de história seja pensada como um conjunto de ações que possa "otimizar" aqueles saberes que o aluno ou o professor já possui sobre história.

A pesquisa em Educação Histórica procura levantar quais são estes saberes na medida em que um novo conhecimento se origina a partir de conhecimentos anteriores e a meta é tornar mais elaborados os modelos de interpretação da história. No caso dos professores, o que entendem por história (conceitos históricos) promove a reflexão sobre currículos escolares, cursos de 
formação e de atualização. O levantamento do conhecimento prévio dos sujeitos escolares apenas é importante se o objetivo último é prospectivo, ou seja, a reflexão e a ação a partir dos dados investigados, - então categorizados e analisados -, servirem ao propósito da reflexão e da ação, no sentido de empreender mudanças significativas no ensino/aprendizado histórico visando a "qualidade".

A literacia história seria uma construção do conhecimento histórico através do princípio investigativo, foram utilizadas algumas fontes. Para Peter Lee, a literacia histórica demanda um "compromisso de indagação" com as "marcas de identificação" da História, como "passado", "acontecimento", "evento", "causa", "mudança", etc., "o que requer um conceito de evidência" (LEE, 2006, p. 136). Assim, o uso da fonte histórica é, ao mesmo tempo, uma metodologia didático-pedagógica importante para a Educação Histórica, bem como um material que serve de mote à percepção sobre como os professores entendem a literacia histórica, o princípio investigativo como base do fazer do professor. Na investigação histórica, seja escolar ou acadêmica: "os documentos não serão tratados como fim em si mesmos, mas deverão responder às indagações e às problematizações de alunos e professores" (SCHMIDT; CAINELLI, 2009, p. 117).

\section{Referências}

ASHBY, R. Desenvolvendo um conceito de evidência histórica: as ideias dos estudantes sobre testar afirmações factuais singulares. Educar, Curitiba, Especial, p. 151-170, 2006. Editora UFPR.

BARCA, I. Aula Oficina: do Projeto à Avaliação. In. (Org.). Para uma educação de qualidade: Atas da Quarta Jornada de Educação Histórica. Braga, Centro de Investigação em Educação (CIED)/ Instituto de Educação e Psicologia, Universidade do Minho, 2004, p. 131 - 144.

BRASIL. DIRETRIZES CURRICULARES NACIONAIS DA EDUCAÇÃO BÁSICA HISTÓRIA - MEC - 2012.

BRASIL. DIRETRIZES CURRICULARES NACIONAIS DO CURSO DE HISTÓRIA MEC - Parecer CNE/CES 492/2001.

BRASIL. PARÂMETROS CURRICULARES NACIONAIS: HISTÓRIA /Secretaria de Educação Fundamental. Brasília: MEC /SEF, 1998. 
FOSENCA, S. G. Didática e prática de Ensino de história. Campinas, SP: Papirus, 2003.

LEE, P. Nós fabricamos carros e eles tinham que andar a pé: compreensão das pessoas do passado. In: BARCA, I. (Org.). Educação histórica e museus. Braga: Centro de Investigação em Educação; Instituto de Educação e Psicologia; Universidade do Minho, 2003.

Putting principles into practice: understanding history. In: BRANSFORD, J. D.; DONOVAN, M. S. (Eds.). How students learn: history, math and science in the classroom. Washington, DC: National Academy Press, 2005.

Em direção a um conceito de Literacia histórica. Educar, Curitiba, Especial, p. 131-150, 2006. Editora UFPR.

RÜSEN, Jörn. Aprendizagem histórica: fundamentos e paradigmas. Curitiba: W.A. Editores, 2012.

Razão histórica. Teoria da História: os fundamentos da ciência histórica. Brasília: Editora Universidade de Brasília, 2001.

Reconstrução do passado. Teoria da História II: os princípios da pesquisa histórica. Brasília: Editora Universidade de Brasília, 2007.

História viva. Teoria da História III: formas e funções do conhecimento histórico. Brasília: Editora Universidade de Brasília, 2007.

OLIVEIRA, T. A. D. de. A Relação ensino e aprendizagem como práxis: a educação histórica e a formação de professores. Mestrado, UFPR. Curitiba, 2012.

THEOBALD, H. A experiência de professores com ideias históricas: o caso do "grupo araucária" / Henrique Rodolfo Theobald. Mestrado, UFPR. Curitiba, 2007.

SCHMIDT, M. A.; BARCA, I.; MARTINS, E. de R. (Org.). Jörn Rüsen e o ensino de História. Curitiba: Ed. UFPR, 2010.

2009.

; CAINELLI, MARLENE. Ensinar história. 2 ed., São Paulo: Scipione,

Recebido em 08 de Setembro de 2014.

Aprovado em 05 de março de 2015. 